\title{
A EDUCAÇÃO FÍSICA NA EDUCAÇÃO ESCOLAR INDÍGENA: A PRODUÇÃO ACADÊMICO-CIENTÍFICA NA ÁREA 21 COMO PERSPECTIVA DE DIÁLOGO E (RE) CONHECIMENTO INTERCULTURAL
}

ACADEMIC-SCIENTIFIC PRODUCTION IN AREA 21 AS A PERSPECTIVE FOR DIALOGUE AND INTERCULTURAL RECOGNITION/KNOWLEDGE

LA EDUCACIÓN FÍSICA EN LA EDUCACIÓN ESCOLAR INDÍGENA: LA PRODUCCIÓN ACADÉMICA Y CIENTÍFICA EN EL ÁREA 21 COMO PERSPECTIVA DE DIÁLOGO Y (RE)CONOCIMIENTO INTERCULTURAL

\section{Lucas Silva Skolaude*, Edwin Alexander Canon-Buitrago**, Fabiano Bossle*}

Palavras chave: Educação Física. Cultura Indígena. Interculturalidade. Revisão.

Keywords: Physical Education. Indigenous culture. Interculturality. Review.

Palabras clave: Educación Física. Cultura Indígena Interculturalidad. Revisión.
Resumo: $O$ estudo tem por objetivo analisar a produção acadêmico-científica sobre a Educação Física, centrada na Educação Escolar Indígena. As buscas foram realizadas no Catálogo de Teses e Dissertações da CAPES e nos periódicos nacionais da Educação Física e da Educação que publicam na Área 21. Durante o agrupamento temático das materialidades encontradas, a interculturalidade ganhou relevância devido ao diálogo que suas produções apresentam para Educação Escolar Indígena e da Educação Física. A dialogicidade é categoria central de análise em razão de apresentar uma perspectiva crítica relações muito próximas entre a visão intercultural e os saberes que a Educação Física pode desenvolver para o reconhecimento desse "outro" cultural. O resultado de análise foi à interpretação de uma "subalternidade" no tratamento das questões indígenas no campo da Educação Física e nos periódicos que publicam na área 21.

Abstract: This study analyzes academic-scientific production on Physical Education, specifically focused on Indigenous School Education. Searches were conducted in CAPES's Catalog of Thesis and Dissertations as well as on Brazilian journals on Physical Education and Education published in the so-called Area 21. During the process of grouping the material found by themes, interculturality gained relevance due to the dialogue that its productions present both for Indigenous School Education and for Physical Education. Dialogue is the central category of analysis because it presents, from a critical perspective, the very close relations between the intercultural vision and the knowledges that Physical Education can develop for the recognition of this cultural "other". The analysis found "subalternity" in the treatment of indigenous people in the field of Physical Education and in journals that publish in area 21

Resumen: El estudio tiene por objetivo analizar la producción académicocientífica sobre la Educación Física, centrada la Educación Escolar Indígena. Las búsquedas se realizaron en el Catálogo de Tesis y Disertaciones de la CAPES y en los periódicos y revistas nacionales de Educación Física y de Educación que se publican en el Área 21. Durante el agrupamiento temático de los materiales encontrados, la interculturalidad ganó relevancia debido al diálogo que sus producciones presentan para Educación Escolar Indígena y Educación Física. La dialogicidad es categoría central de análisis al presentar en una perspectiva crítica relaciones muy próximas entre la visión intercultural y los saberes que la Educación Física puede desarrollar para el reconocimiento de ese "otro" cultural. El resultado del análisis fue la presencia de una "subalternidad" en relación al tratamiento de las temáticas indígenas en el campo de la Educación Física y en los periódicos y revistas que publican en el Área 21.
* Universidade Federal do Rio Grande do Sul (UFRGS). Porto Alegre, RS, Brasil. E-mail:

lucasskolaude@hotmail.com fabiano.bossle@ufrgs.br

** Universidad de la República (UDELAR), Uruguai. E-mail: infamar12@gmail.com

Recebido em: 01-02-2019 Aprovado em: 11-02-2020 Publicado em: 23-02-2020 


\section{INTRODUÇÃO}

O presente estudo tem por objetivo analisar e discutir a produção acadêmicocientífica sobre a Educação Física, componente curricular obrigatório para educação básica, conforme a Lei de Diretrizes e Bases (LDB) 9394/96 (BRASIL, 1996), centrada especificamente no âmbito da Educação Escolar Indígena. Para tal, realizamos uma revisão sistemática entendendo que seu objetivo é identificar, mapear e analisar as produções disponíveis a respeito da temática pesquisada (SAMPAIO; MANCINI, 2007).

As correspondentes buscas foram realizadas em duas fases: a primeira, no Catálogo de Teses e Dissertações da Coordenação de Aperfeiçoamento de Pessoal de Nível Superior (CAPES) com a intenção de conhecer as distintas produções realizadas nos programas de pós-graduação do país sobre a temática em questão, para logo, procurar nos periódicos nacionais da Educação Física e da Educação que publicam na Área $21^{2}$ considerando que muitos dos estudos que abordam este tipo de temática não circulam exclusivamente no campo específico da Educação Física.

Nosso interesse na revisão da produção científica sobre o tema emerge da construção da primeira dissertação de mestrado acadêmico que visa compreender o ensino do componente curricular da Educação Física no âmbito de uma Escola Estadual Indígena Kaingang no município de Porto Alegre - RS.

A legislação que configura atualmente as escolas indígenas reconhece os direitos dos povos indígenas, tal como versa nos artigos $210^{3}$ e $231^{4}$ da Constituição Federal (CF) de 1988, quanto à sua organização social, costumes, línguas, crenças e tradições como direito assegurado e inalienável.

A Educação Escolar Indígena, além de se encontrar amparada pela Constituição Federal (1988) é regulamentada pelo Referencial Curricular Nacional para as Escolas Indígenas ${ }^{5}$ (RCNEI) (1998), o qual estabelece que sua estrutura e funcionamento estará direcionada a partir de 3 eixos fundamentais: o primeiro relacionado a educação diferenciada, pois esta é concebida e planejada obedecendo aos interesses, necessidades e as particularidades étnico-culturais representativas de cada povo ou comunidade. O segundo, o intercultural que visa estabelecer diálogos entre as tradições, conhecimentos, culturas e saberes próprios das sociedades indígenas, bem como sua interação com experiências, racionalidades e práticas das sociedades não indígenas. Por fim, o bilíngue, pois a (re)produção sociocultural das

\footnotetext{
1 § 30 A Educação Física, integrada à proposta pedagógica da escola, é componente curricular obrigatório da educação básica, sendo sua prática facultativa ao aluno: I - que cumpra jornada de trabalho igual ou superior a seis horas; II - maior de trinta anos de idade; III - que estiver prestando serviço militar inicial ou que, em situação similar, estiver obrigado à prática da Educação Física; IV - amparado pelo Decreto-Lei no 1.044, de 21 de outubro de 1969; (Incluído pela Lei $n^{\circ} 10.793$, de $1^{\circ} .12 .2003$ que trata de basicamente de portadores de doenças que precisam que tratamento excepcional) V - Vetado; VI - que tenha prole.

2 A área 21 é formada por programas de Pós-graduação, que envolvem quatro áreas de atuação acadêmica e profissional: Educação Física, Fisioterapia, Fonoaudiologia e Terapia Ocupacional. A área é bastante diversificada em termos de suas vocações, as quais variam desde as áreas biológicas e médicas até as áreas pedagógicas, sociais e humanas (CAPES).

3 Disponível em: http://www.senado.leg.br/atividade/const/con1988/con1988 12.07.2016/art 210_asp. Acesso em: $18 / 09 / 2018$

4 Disponível em: https://www.senado.leg.br/atividade/const/con1988/con1988 08.09.2016/art 231 .asp. Acesso em: 24/09/2018

5 Disponível em: http://www.dominiopublico.gov.br/download/texto/me002078.pdf. Acesso em: 09/10/2018
} 
sociedades indígenas é manifestada por meio da memória, uso e transmissão de saberes em mais de uma língua.

O Referencial Curricular Nacional para as Escolas Indígenas, ao abordar os componentes que dele fazem parte, enfatiza num conjunto de Temas Transversais, os quais permitem estabelecer um elo de discussão entre diversas áreas de estudo (as Línguas, a Matemática, a História, a Geografia, as Ciências e a Educação Física) e o projeto social e cultural que cada um dos povos e/ou suas comunidades visam desenvolver. Desse modo, ao se aproximar especificamente da área da Educação Física o supracitado referencial estabelece três eixos principais para o desenvolvimento desse componente na Educação Escolar Indígena: o primeiro relacionado à cultura corporal do próprio povo, o segundo a cultura corporal de outros povos indígenas e o terceiro a cultura corporal da sociedade envolvente (nacional e internacional).

Contudo, apesar de nosso entendimento de que essa população é contemplada nos marcos legais, interpretamos que uma parcela significativa dos povos originários vive em situação de subalternidade nos seus mais diversos aspectos, dentre eles o populacional, cultural, territorial e social (PADOIN; VIRGOLIN, 2010), de modo que suas culturas se tornam invisíveis no processo de reconhecimento da perspectiva de ideais ainda colonialistas e opressoras.

Nesse sentido, buscamos apoio em Paulo Freire $(1979,2005,2017)$ para articular suas importantes contribuições junto a temática pesquisada, cientes de que o referido autor não escreveu especificamente sobre a Educação Física, ou, sobre a Educação Escolar Indígena, mas dedicou sua obra a combater uma educação bancária homogeneizante e não crítica, direcionada ao controle e manutenção das estruturas de opressão e dominação. Em Pedagogia do Oprimido, por exemplo, Freire (2017), menciona a importância de uma educação humanista e libertadora para desvelar aos oprimidos as estruturas hegemônicas, partindo especificamente da problematização crítica da realidade dos sujeitos auxiliando no processo de emancipação da sociedade dominada.

A partir do exposto, o artigo se encontra dividido em três seções: $\mathrm{Na}$ primeira intitulada "Delineamento geral das buscas", é apresentado o percurso realizado para o mapeio, buscas e organização da informação proveniente tanto do repositório especificado quanto dos distintos periódicos que publicam na Área 21. Na segunda seção denominada "Dialogicidade/Interculturalidade na Educação Física: possibilidades de (re)conhecimento na Educação Escolar Indígena”, é desenvolvido o processo de análise estabelecendo relações entre a dialogicidade e a interculturalidade como processo de reconhecimento e emancipação cultural, para seguidamente nas "Considerações Finais" apresentar os resultados e interpretações do processo de construção da correspondente revisão sistemática.

\section{DELINEAMENTO GERAL DAS BUSCAS}

Com intuito de realizar uma revisão sistemática sobre o estado da arte na produção científica que aborda a Educação Física na Educação Escolar Indígena, decidimos realizar inicialmente uma busca no Catálogo de Teses e Dissertações 
(CAPES), para seguidamente procurar nos periódicos da Educação Física e da Educação, em que ocorrem publicações da Educação Física. As supracitadas buscas obedecem inicialmente a congregação que o repositório oferece em relação às pesquisas realizadas nos programas de pós-graduação no Brasil para área da Educação Física, assim como o prestígio que acreditam os periódicos que fazem parte da área 21 em relação à circulação, qualidade e rigorosidade na avaliação de estudos, experiências e reflexões acerca da temática pesquisada.

Para desenvolver as respectivas indagações foram inseridos no buscador correspondente um conjunto de termos de busca: "Educação Física Escolar indígena", "Educação Física na Escola Indígena" e "Educação Física" and "Escola Indígena" tanto para o catálogo de teses e dissertações quanto para os diversos periódicos que conformam a classificação da Área 21. As buscas na base de dados citadas, foram realizadas no mês de agosto de 2018 e retomadas em Dezembro de 2018, para conferência. Como critérios de inclusão/exclusão foram selecionadas mediante leitura dos títulos e resumos as produções nacionais em língua portuguesa disponíveis de forma online e gratuita sem nenhum tipo de limitação temporal e que contribuíam para alcançar o objetivo proposto.

No catálogo de teses e dissertações da CAPES, foram selecionados o total das produções disponibilizadas (8) nos distintos termos de busca. Em relação aos periódicos da Educação Física que publicam na área 21 foram pesquisados aqueles que se encontram classificados entre Qualis ${ }^{6} \mathrm{~A} 2$ e $B 5^{7}$, enquanto que, para os periódicos do campo da Educação foram pesquisados ${ }^{8}$ aqueles que se classificam entre os estratos B2 e B4 do Qualis mencionado.

Como resultado desse processo de buscas, foram encontradas 1 tese de doutorado, 7 dissertações de mestrado e 6 artigos científicos que abordam de forma direta a Educação Física no contexto da Educação Escolar Indígena. Para a organização do conjunto total das materialidades encontradas nas buscas, foi necessário a criação de grupamentos por proximidade temática com o objetivo de identificar essencialmente o tipo de abordagem que cada uma das produções textuais apresenta acerca do assunto pesquisado. Este grupamento se deu a partir da leitura na integra de cada texto.

Como síntese desse movimento e tal como o mostra o quadro 1 (na próxima página), foram aglutinadas as 14 produções em 4 grupamentos temáticos contemplados da seguinte forma: Interculturalidade (6), Cultura corporal (4), Formação de professores indígenas (2) e Política pública (2).

6 Qualis referente ao quadriênio 2013-2016 pois até o momento não houve atualização na área 21.

7 Periódicos da EFI que fazem parte da área 21 segundo classificação no qualis: $\mathbf{A} 2-1$; $\mathbf{B} 1-4 ; \mathbf{B} 2-2 ; \mathbf{B} 3-1 ; \mathbf{B} 4-6$; B5-3.

8 Periódicos da área da Educação que fazem parte da área 21 segundo classificação no qualis: B2-11; B3-1; B4-28. 
Quadro 1 - Resultado geral do processo de busca

\begin{tabular}{|c|c|c|c|c|c|}
\hline \multirow{8}{*}{ 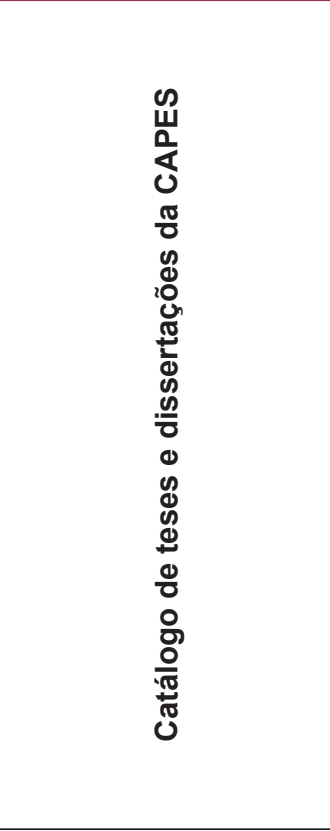 } & Tipo & Título & Autor & Ano & Grupamento \\
\hline & Dissertação & $\begin{array}{c}\text { Saberes Tradicionais Krahô: Contribuições para Educação Física } \\
\text { Indígena Bilíngue e Intercultural }\end{array}$ & Francinaldo Freitas Leite & 2017 & Interculturalidade \\
\hline & Tese & $\begin{array}{c}\text { Educação Física NA/DA Escola Indígena: Apropriações e } \\
\text { ressignificações numa Aldeia Bororo }\end{array}$ & Juliana Guimarães Saneto & 2016 & Interculturalidade \\
\hline & Dissertação & $\begin{array}{c}\text { Práticas Corporais Indígenas Inseridas a Educação Física } \\
\text { Escolar não Indígenas }\end{array}$ & Gédson Cardoso Kempe & 2015 & Interculturalidade \\
\hline & Dissertação & $\begin{array}{c}\text { A Educação Física na Escola Indígena: a cidadania e a } \\
\text { emancipação indígena em questão }\end{array}$ & Keros Gustavo Mileski & 2013 & Política Pública \\
\hline & Dissertação & $\begin{array}{l}\text { Tessituras da Cultura Corporal em uma Escola Indígena do Alto } \\
\text { Rio Netro no Estado do Amazonas }\end{array}$ & Jhones Rodrigues Pereira & 2013 & Cultura Corporal \\
\hline & Dissertação & $\begin{array}{c}\text { Jogos de Origem ou descendência indígena e africana na } \\
\text { Educação Física Escolar: Educação para e nas Relações Étnico } \\
\text { Raciais }\end{array}$ & Clovis Claudino Bento & 2012 & Cultura Corporal \\
\hline & Dissertação & $\begin{array}{l}\text { A Educação Física Escolar na Escola Municipal Indígena } \\
\text { "Marcolino Lili": uma Possibilidade de Fortalecimento Étnico }\end{array}$ & Alfredo Anástacio Neto & 2007 & Interculturalidade \\
\hline Nome do Periódico & Qualis & Título & Autor(es) & Ano & Grupamento \\
\hline $\begin{array}{l}\text { Revista de Educação } \\
\text { Pública (UFMT) }\end{array}$ & B4 & $\begin{array}{c}\text { Práticas Corporais Indígenas Inseridas a Educação Física } \\
\text { Escolar não Indígenas }\end{array}$ & $\begin{array}{l}\text { Gédson Cardoso Kempe; } \\
\text { Attico Inácio Chassot }\end{array}$ & 2017 & Cultura Corporal \\
\hline $\begin{array}{l}\text { MOVIMENTO } \\
\text { (UFRGS) }\end{array}$ & $\mathrm{A} 2$ & Os Kaingang do Ivai, suas Danças e a Educação Intercultural & $\begin{array}{l}\text { Juliana Dias Boaretto; } \\
\text { Giuliano Gomes de Assis } \\
\text { Pimentel }\end{array}$ & 2015 & Interculturalidade \\
\hline HORIZONTES & $\mathrm{RA}$ & $\begin{array}{l}\text { Educação Física Escolar no Curso de Formação em Nível Médio } \\
\text { para Professores Guarani e Kaiowá: Memória da Turma } 2001\end{array}$ & André Vinícius Hidalgo & 2014 & $\begin{array}{l}\text { Formação de } \\
\text { Professores }\end{array}$ \\
\hline Revista de Educação & B4 & Educação Física Intercultural: Diálogos e Brincadeiras Guarani & $\begin{array}{l}\text { Gislaine Ferreira; Giuliano } \\
\text { Gomes de Assis Pimentel }\end{array}$ & 2013 & Interculturalidade \\
\hline $\begin{array}{l}\text { Atos em Pesquisa } \\
\text { em Educação (FURB) }\end{array}$ & B4 & O Corpo Indígena: Apontamentos Para outra Educação Física & $\begin{array}{l}\text { Renato Izidoro da Silva; } \\
\text { Miguel Angel Garcia } \\
\text { Bordas }\end{array}$ & 2012 & Cultura Corporal \\
\hline $\begin{array}{c}\text { Revista } \\
\text { Corpoconsciência }\end{array}$ & B4 & $\begin{array}{c}\text { Cultura Indígena: um Novo Olhar a Partir das Práticas Esportivas } \\
\text { e das Brincadeiras Tradicionais Vivenciadas na Escola }\end{array}$ & Rosana de Barros Gabriel & 2006 & $\begin{array}{l}\text { Formação de } \\
\text { Professores }\end{array}$ \\
\hline
\end{tabular}

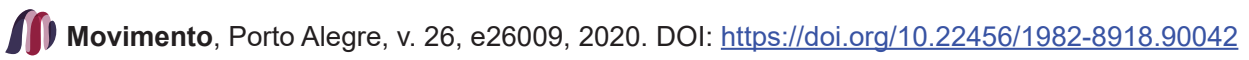


No grupamento "Interculturalidade" foram aproximadas 3 dissertações de mestrado, 1 tese de doutorado e 2 artigos científicos que reúnem trabalhos em relação a interculturalidade como processo de (re)conhecimento, diálogo, construção e interação entre a racionalidade indígena e "outras" racionalidades culturais. O grupamento "Cultura corporal" concentra 4 produções (2 dissertações, 2 artigos) orientadas a tratar, entender e discutir questões relacionadas ao corpo e as práticas corporais indígenas na Educação Física como componente curricular tanto para a escola indígena quanto para a escola regular. Com dois artigos, o agrupamento "Formação de professores" reúne contribuições orientadas ao relato e registro de experiências de formação nas aulas de Educação Física para dois cursos de formação de professores indígenas de nível meio. Já no grupamento "Política Pública", identificamos duas produções direcionadas a oferecer subsídios e ferramentas ao pessoal docente e administrativo das escolas indígenas para garantir os limites e possibilidades da implantação, ensino e aprendizagem dos distintos componentes curriculares que integram a Educação Escolar Indígena entre os que se encontra a Educação Física.

Dos 4 grupamentos em que se concentraram os achados das buscas, o grupamento "interculturalidade" ganhou destaque no processo de construção de sentidos para a prospecção das análises devido a que sua ressonância aglutinou produções com temáticas diferenciadas, mas muito interligadas a Educação Escolar Indígena e sua interface com o componente curricular da Educação Física.

No grupamento "Interculturalidade", a dissertação de Leite (2017) propõe uma abordagem pedagógica para o ensino da Educação Física no contexto escolar indígena Krahô. De forma geral, visa a preservação, ensino, aprendizagem e prática dos saberes próprios desse povo mediante um currículo intercultural e bilíngue cuja proposta esteja direcionada a compreender o sujeito como construtor de cultura desde o movimento, o lúdico e o corporal. De forma similar, Saneto (2016), procura compreender o componente curricular da Educação Física na escola indígena "Korogedo Paru" a partir de uma perspectiva intercultural. Nesta lógica, a autora identifica o componente curricular como o único a trabalhar nos seus conteúdos a cultura corporal de movimento visando uma ressignificação crítica, conceitual e reflexiva da área em prol de criar novas possibilidades de diálogo e produção de conhecimentos relacionadas com suas práticas culturais.

Nessa linha, Kempe (2015) busca a compreensão sobre as práticas corporais indígenas na composição dos currículos da Educação Física escolar, procurando a construção de uma proposta na perspectiva de educação intercultural. Dessa forma, houve a tentativa de levar um conjunto de práticas culturais desses povos à educação escolar não indígena propondo assim, uma aproximação com as distintas manifestações culturais que tradicionalmente não fazem parte dos conteúdos a serem considerados pela disciplina na escola regular.

Pela sua parte, Anastácio Neto (2007) realiza uma série de discussões e críticas em relação a diversidade e a necessária quebra de estruturas e paradigmas que tem direcionado a disciplina ao longo do tempo, levando a considerar que a abordagem de certos conteúdos científico-acadêmico no campo da Educação Física 
e mais especificamente na Educação Escolar Indígena não atende aos objetivos interculturais que o Referencial Curricular Nacional para as Escolas Indígenas propõe para ser trabalhados nesse contexto.

O artigo de Boareto e Piementel (2015) teve o intuito de discutir a dança da etnia Kaingang na perspectiva da educação intercultural, buscando contribuir com a efetivação da lei $11.645 / 0^{9}$ (BRASIL, 2008). Conforme os autores, por meio da educação intercultural é possível estabelecer diálogos de pensamento do "outro" para reconfigurar, alimentar e reafirmar a existência dos povos indígenas e em especial da cultura Kaingang nos seus diversos espaços de interação social e cultural.

Por último, Ferreira e Pimentel (2013) realizam alguns apontamentos em relação a abordagem das temáticas indígenas nas aulas de Educação Física, tendo como ponto de partida a educação intercultural e seus diversos referentes conceituais. Nesse sentido, os autores manifestam a importância de tematizar nas aulas de Educação Física (na escola regular ou indígena) a cultura corporal dos povos indígenas e em especial algumas práticas culturais como jogos e brincadeiras, já que dessa forma se possibilita o estudo, interação e aproximação a esses assuntos com a finalidade de potencializar nos educandos os sentidos e significados que essas práticas adquirem nas diferentes realidades culturais.

Durante a organização e leitura atenta de nosso material empírico, chamounos a atenção a relevância que a interculturalidade - como perspectiva de diálogo, aproximação e reconhecimento desse "outro" cultural - apresenta na Educação Escolar Indígena e sua conexão com o componente curricular da Educação Física, pois é neste espaço que se estabelecem relações dialógicas entre o educando, seus interlocutores e as múltiplas formas culturais de vivenciar o mundo.

A esta ação de (re)conhecimento, interação e diálogo, Freire (2017) denominou de dialogicidade, já que é um processo de educação crítica que liberta, humaniza, outorga sentido e problematiza a dimensão existencial, ética e política dos sujeitos com a finalidade de compreender e transformar sua realidade. Nesta linha, a dialogicidade como elemento central para o reconhecimento e interação com o "outro", oportuniza um espaço de respeito e igualdade entre sujeitos, práticas e culturas, pois, como menciona Carmo e Gonçalves (2008), as "pessoas só significam as coisas a partir de suas experiências vividas e, como cada sujeito é único, uma mesma situação pode gerar diferentes experiências em diferentes pessoas" ( $p$. 3079).

Neste caso, a dialogicidade se converte em nossa categoria central de análise, já que estabelece relações muito próximas com a interculturalidade e a Educação Física, permitindo uma dinamicidade crítica nas formas de interatuar com os outros, seus conhecimentos e a aproximação aos saberes que transformam os sujeitos e o mundo-vida que os rodeiam.

9 A lei 11.645/2008 estabelece as diretrizes e bases da educação nacional, para incluir no currículo oficial da rede de ensino a obrigatoriedade da temática "História e cultura afro-brasileira e indígena". Isso implica a necessidade de abordar a temática em questão no ensino de todas as disciplinas do currículo da educação básica, que inclui o ensino fundamental e médio. Maiores Informações:Disponível em: http://www.planalto.gov.br/ccivil_03/_ato2007-2010/2008/ lei//11645.htm. Acesso em: 20 out.2018. 


\section{DIALOGICIDADE/INTERCULTURALIDADE NA EDUCAÇÃO FÍSICA: POSSIBILIDADES DE (RE)CONHECIMENTO NA EDUCAÇÃO ESCOLAR INDÍGENA}

Consciente da real situação ao qual se encontram milhares de oprimidos no Brasil e na América Latina, Paulo Freire (2017), em sua obra "pedagogia do oprimido", oferece um dos eixos principais da sua teoria direcionada ao diálogo, como elemento emancipatório para prática da liberdade, comprometido com a educação, a vida e a existência que conscientiza criticamente o sujeito no seu contexto histórico social.

Partindo desta ideia, o diálogo, na lente de Freire, seria entendido como aquele momento em que os sujeitos se encontram para refletir criticamente o meio, sua cultura e a cultura dos "outros", confrontando assim o aprisionamento em que se estrutura a educação antidialógica, baseada na homogeneização do conhecimento (educação bancária) e nas relações de poder, já que, como menciona Freire e Faundez (1985) "o diálogo só existe quando aceitamos que o outro é diferente e pode nos dizer algo que não conhecemos” (FREIRE; FAUNDEZ, 1985, p. 36).

Para Freire, a dialogicidade é tratada a partir da ação e reflexão; é o sujeito que aprende em contato com o outro, com sua cultura, experiências, identidades e diferenças.

O diálogo tem significação precisamente porque os sujeitos dialógicos não apenas conservam sua identidade, mas a defendem e assim crescem um com o outro. O diálogo por isso mesmo, não nivela, não reduz um ao outro. Nem é favor que um faz ao outro. (FREIRE, 1993, p. 118).

Neste sentido, a função dialógica na educação se estabelece como ponto de partida para desenvolver o conhecer humano mediante um processo de relação intercomunicativa que liberte ao sujeito das estruturas de opressão criando possibilidades de escuta, existência, reflexão e transformação do mundo. Transformação que leve à interação dos educandos com segmentos sociais, políticos, éticos, econômicos e culturais a partir da constituição de relações horizontais (simétricas e intersubjetivas) onde prevaleça a autonomia, a humanização dos sujeitos, o afeto e a problematização da realidade.

Sendo assim, o diálogo na educação só será possível no momento em que aceitamos a diferença cultural do outro (sua história, vida, formas de interpretar o mundo) e estabelecemos relações de comunicação intercultural que nos leve a compreender de forma consciente a existência social dos outros. Desta forma, a educação só teria sentido com dialogicidade, como encontro de falas que gera vida comum, convivência, harmonia, na alteridade, entendimento entre seres diversos (SANTOS, 2017).

Para Canon-Buitrago (2017), o movimento intercultural se desenvolve a partir de um conjunto de lutas sociais, especificamente dos povos indígenas, em países latino-americanos como Equador, Peru, Bolívia e México, onde se negava a visibilidade o reconhecimento e a integração de grupos ancestrais culturalmente subalternos em espaços políticos, econômicos e educativos.

É precisamente desde a interculturalidade que é possível consolidar políticas, discussões e debates em relação à diferença cultural como 
caminho para o reconhecimento de epistemes diversas, não somente para indígenas, quilombolas ou para a população das áreas rurais, mas também para todos aqueles grupos minoritários que integram uma sociedade nacional, possibilitando assim o acesso a novas estruturas de subjetividades, conhecimentos e saberes até o momento pouco valorizados pelo contexto cidadão e pelo modelo de civilização global na qual habitamos. (CANONBUITRAGO, 2017, p. 78).

Para que seja possível o estabelecimento de diálogo entre os sujeitos, suas culturas, seus saberes e práticas, é necessário que existam condições de igualdade entre os diferentes grupos que conformam a sociedade, pois é a igualdade o elemento central pelo qual a interculturalidade - como processo contra-hegemônico - busca refletir e repensar as distintas dualidades de subalternização e classificação universal em que se encontram rotulados os seres humanos. Nessa linha, acreditamos que tanto a dialogicidade quanto a interculturalidade se complementam entre si, devido ao desafio, possibilidade e oportunidade de fazer compreender, enxergar e refletir nos sujeitos as múltiplas formas de pensar a educação, a sociedade, a construção de identidade e os sentidos e significados que as práticas corporais culturais adquirem no componente curricular da Educação Física tanto na educação regular quanto na Educação Escolar Indígena.

Trata-se de reconhecer possíveis horizontes de reformulação intercultural enquanto projeto social, político e epistemológico, partindo da aceitação de que o conceito de interculturalidade está carregado simbolicamente de imaginários diversos. $\mathrm{O}$ fato de que o mesmo não esteja conformado por uma base de significados estáveis, nem necessariamente compartilhados, mas por sentidos que representam uma variedade de posições dinâmicas, tanto individuais como coletivas, integra a realidade e o problema a serem enfrentados e assumidos em sociedades atravessadas por desigualdades de todo tipo, nas quais o acesso à escola e à escolaridade contribuem para essa iniquidade. (WALSH, 2008, p. 56).

Considerando o supracitado, Leite (2017) traz a tona como os povos indígenas produzem vivenciam e expressam suas concepções de mundo. Concepções que devem ser respeitadas salientando que o currículo e as disciplinas devem dialogar com a diversidade de conhecimento desde uma perspectiva intercultural e bilíngue tal como o prevê o Referencial Curricular Nacional para as Escolas Indígenas.

[...] em função de oportunizar o diálogo entre os saberes ou epistemes, a interculturalidade aparece como um princípio que orienta pensamentos, ações e novos enfoques. O conceito de interculturalidade é central na (re) construção do pensamento-outro, desta maneira a interculturalidade é concebida, como um processo e também um como projeto político (LEITE, 2017, p. 87).

$\mathrm{Na}$ análise do contexto socio-histórico do país devemos elucidar que a sociedade dominante subalternizou os conhecimentos, práticas e saberes indígenas em nome de um progresso científico e desigual. Como contraponto desse parâmetro classificatório é que a educação intercultural visa a valorização de diferentes epistemologias como instrumentos de construção dinâmica de conhecimento e identidade.

Saneto (2016), faz uma reflexão sobre a interculturalidade na Educação Escolar Indígena entendendo-a como processo de construção e solidificação de uma sociedade democrática, inclusiva e pluralista articulando políticas de igualdade como ferramenta de diálogo para contextos diferenciados, em prol da interação e 
valorização de práticas entre os sujeitos que circulam nesses espaços escolares. A autora menciona que "a educação escolar diferenciada, como direito, nasce de um amplo campo da diversidade sociocultural no país, submetido historicamente às práticas homogeneizadoras, geradoras de desigualdades e injustiças sociais" (SANETO, 2016, p. 76).

Pensando nisso, Freire (2017) menciona que:

[...] é na realidade mediatizadora, na consciência que dela tenhamos educadores e povo, que iremos buscar o conteúdo programático da educação. O momento deste buscar é o que inaugura o diálogo da educação como prática da liberdade. É o momento em que se realiza a investigação do que chamamos Universo Temático do povo ou o conjunto de seus temas geradores" (FREIRE, 2017, p.101).

Nesta esteira do pensamento, entendemos que a Educação Escolar Indígena além de ajudar a recuperar sua história, conhecimentos, valores, pretensões socias e culturais, deve lutar contra ás desigualdades que se apresentam frente ás outras racionalidades, posicionando-se de forma crítica e política para garantir sua visibilidade, ampliação e cumprimento dos seus direitos. É pertinente também mencionar que esse posicionamento só ocorrerá através da dialogicidade entre o homogêneo e o diverso, o real e o verdadeiro, o comum e o científico, pois como menciona Gadamer (2007) "a incapacidade para dialogar é em última instância sempre o diagnóstico de alguém que não se presta ao diálogo e não consegue entrar em diálogo com o outro" (GADAMER, 2007, p. 250).

É justamente sobre a escola, seus espaços, os saberes escolares e as relações dialógicas a serem estabelecidas entre contextos e educandos, que Oliveira (2017) salienta a necessidade de um ensino que apresente

\section{[...] como ponto de partida o saber da criança, as situações existenciais e sociais vivenciadas por ela, a curiosidade e a lógica de construção do pensamento elaborados pela criança em relação ao contexto em que vive e que conta como as estratégias pedagógicas preparadas pelos educadores para relacionar os saberes das crianças com os saberes escolares (OLIVEIRA, 2017, p. 245).}

Com ponto de vista semelhante, Leite (2017) sinaliza que trabalhos desenvolvidos no âmbito da Educação Física, possibilitam refletir as temáticas indígenas na promoção de diálogos interculturais e de conhecimentos escolares. Para que esta perspectiva de diálogo intercultural seja alcançada, deve haver preocupação e cuidado com esse "outro" e a forma como esse "outro" é considerado. Nessa lógica, a prática intercultural deve estar longe de qualquer rótulo ou preconceito fazendo que o princípio da alteridade seja legitimado nas diversas relações culturais que os sujeitos estabelecem entre si. Em poucas palavras, a educação intercultural deve ser abrangente e considerar as diversas alteridades que disputam legitimidade nas variadas formas de ser, viver, interatuar e interpretar o mundo.

Compreendendo que a Educação Física historicamente tem carregado discursos biológicos de características hegemônicas-coloniais e considerando que a sua inclusão no Referencial Curricular Nacional para as Escolas Indígenas propicia uma outra abertura a novas possibilidades de estudo, sistematização, reflexão e prática, acreditamos que o componente curricular se converte em um espaço de 
diálogo e conscientização crítica, para ressignificar os sentidos que a cultura corporal dos povos indígenas adquirem tanto na Educação Escolar Indígena quanto na educação regular.

Eis aqui que esse ângulo de ressignificação adquire sentido, pois no momento em que se possibilita o estudo, a interação e abordagem das práticas corporais indígenas como conteúdo a ser tratado na área, se desvirtua a lógica universalmente constituída para o ensino da disciplina no espaço escolar, devido a que se faz necessário assim como imprescindível, o estudo e análise de outras formas de compreender as variadas representações sociais do movimento humano.

Assim, a área de Educação Física escolar pode estar voltada para um primeiro objetivo, compatível com as demandas e realidades indígenas atuais: trata-se de fazer com que o aluno, a partir dos conhecimentos próprios de sua cultura e dos conteúdos aprendidos nas outras disciplinas escolares, conheça e avalie criticamente aqueles elementos da "cultura corporal de movimento" (brincadeiras, jogos, esportes, exercícios de ginástica, danças, lutas etc.) da sociedade envolvente que, na perspectiva indígena, forem mais interessantes e atraentes. (REFERENCIAL CURRICULAR NACIONAL PARA AS ESCOLAS INDÍGENAS, 1998, p. 325).

É assim que queremos sublinhar que, ao trazer para Educação Física novos elementos de reflexão entre estes a cultura corporal dos povos originários, devemos estar em capacidade de contribuir não somente no estudo do resgate dos elementos culturais invisibilizados pela lógica cientificista da disciplina acadêmica, senão também na estimulação do pensamento crítico e intercultural visando a emancipação dos sujeitos daquelas estruturas preconceituosas e homogeneizantes em que a sociedade se encontra imersa.

É desta forma que o componente curricular da Educação Física na Educação Escolar Indígena deve estar aberto a compreender que a cultura corporal de movimento dos povos indígenas - como elemento identitário - é dinâmica e se encontra circulante em espaços culturais, ancestrais e coletivos, pois como menciona Canon-Buitrago (2015), são nesses espaços onde se (re)configuram experiências de interação cosmológicas entre o plano/mundo horizontal (relações sujeito-natureza e relações inter-humanas) e o plano/mundo vertical (relações do sujeito com os espíritos, os mitos, os seres mitológicos, as divindades extra-humanas).

Entendemos que a transformação curricular da Educação Física na Educação Escolar Indígena deve basear-se pelas deliberações da cultura corporal do próprio grupo, a cultura corporal de outros povos e a cultura corporal da sociedade envolvente. Desta forma, compreender as múltiplas subjetividades que representam as diversas práticas corporais (indígenas e não indígenas) permite estudar e dialogar interdisciplinarmente em prol da construção de sentidos e significados não homogêneos em relação a temáticas como a educação, a saúde, o lazer e o esporte.

Nas escolas indígenas, as aulas de Educação Física podem ser um espaço onde as crianças e os jovens comecem a sistematizar as informações e conhecimentos sobre esportes como o vôlei, o futebol e o atletismo, que chegam até eles por meios de comunicação, do contato com não-índios e da prática dos próprios adultos nas comunidades em que vivem. (BRASIL, 1998, p. 325). 
Em fase dessa ideia, a Educação Física como componente curricular da educação e em parceria com outras áreas de conhecimento deve estabelecer um diálogo pedagógico, conceitual e intercultural para a (re)produção de conhecimento científico, humano e de identidade. É por isso que acreditamos que o componente curricular tem a capacidade de (de)construir inúmeras questões sociais, étnicas e culturais que constantemente circulam tanto no senso comum quanto nos diferentes meios de comunicação privilegiando formas exóticas de enxergar os povos originários.

Sobre a importância da dialogicidade nos sentidos de ser, dos seus significados produzidos a partir de uma relação horizontal, assim como o conhecimento adquirido a partir da relação dialógica, exercendo papel emancipador e função libertadora, Freire (2017), destaca:

Por isso, só com o diálogo se ligam assim, com amor, com esperança, com fé um no outro, se fazem críticos na busca de algo. Instala-se, então, uma relação de simpatia entre ambos. Só aí há comunicação. O diálogo é, portanto, o indispensável caminho, não somente nas questões vitais para a nossa ordenação política, mas em todos os sentidos do nosso ser. Somente pela virtual da crença, contudo, tem o diálogo, estímulo e significação: pela crença no homem e nas suas possibilidades, pela crença de que somente chego a ser eles mesmos" (FREIRE, 2017, p. 115-116).

Em compreensão dos aspectos refletidos na categoria de análise e tendo como parâmetro principal a relação estabelecida entre a dialogicidade, a interculturalidade e a Educação Física na Educação Escolar Indígena, foi possível evidenciar que o reconhecimento e interação com o "outro" desde uma visão de igualdade, legitima nos sujeitos o processo de comunicação, reflexão e entendimento em relação a existência cultural, social e subjetiva do outro diferente, fomentando o diálogo com as múltiplas realidades nas quais os sujeitos constantemente transitam.

\section{CONSIDERAÇÕES FINAIS}

Com objetivo de analisar e discutir a produção acadêmico-científica sobre a Educação Física no âmbito da Educação Escolar Indígena, identificamos uma "subalternidade" em relação ao tratamento das questões indígenas e as contribuições que esta temática pode oferecer para o próprio campo acadêmico, considerando os percursos históricos, científicos e práticos nos quais tem sido estruturada a disciplina acadêmica no espaço escolar. Evidencia do supracitado foram as 14 produções encontradas tanto no catálogo de teses e dissertações da CAPES quanto nos periódicos que publicam na Área 21 (Educação Física e Educação) o que destaca a pouca produção acerca da temática pesquisada, considerando que o componente curricular da Educação Física também faz parte do Referencial Curricular Nacional para as Escolas Indígenas desde o ano de 1998.

Nessa linha, constatamos que um dos pontos mais recorrentes nas produções encontradas foi a abordagem da interculturalidade como ponto de diálogo, interação e reflexão das diferenças culturais dos sujeitos que habitam o meio. Compreendemos que a dialogicidade como categoria central de análise, estabeleceu pontos muito próximos da interculturalidade e do componente curricular da Educação Física, já que possibilita a realização de uma reflexão crítica em relação às formas de 
interação entre os sujeitos, suas práticas culturais, suas identidades e as formas como interpretam o mundo.

Desta forma, o estudo nos permitiu entender a Educação Física como disciplina mediadora para o diálogo e a reflexão das relações socioculturais em que o corpo, as práticas corporais e a cultura corporal de movimento adquirem sentidos diversificados provenientes de múltiplas racionalidades entre as que se encontra a indígena.

Compreendemos que a Educação Física tem problematizado poucos estudos no âmbito da Educação Escolar Indígena devido a uma persistente e contundente desvalorização dos saberes críticos produzidos na Educação Física Escolar, onde constantemente se reflete o caráter científico do paradigma dominante negando outras formas de conhecimento que não pautam-se pelas suas concepções epistemológicas (BOSSLE; BOSSLE, 2018). Sobre essa baixa produção de conhecimento alguns autores, como Zilberstein et al., (2016); Goldschimdt Filho et al., (2016) e Bracht et al., (2011), vêm problematizando o baixo número de artigos publicados na área 21, quando se trata de viés pedagógico/sociocultural da Educação Física.

Sendo assim, entendemos a Educação Escolar Indígena e o componente curricular da Educação Física como um campo promissor a ser investigado, pois este lugar também faz parte do acionar social, educativo e profissional da área em que as formas de entender, pesquisar, ensinar e aprender os sentidos da cultura corporal de movimento dos povos indígenas requerem uma outra lógica diferente da historicamente desenvolvida na disciplina escolar.

Finalmente, acreditamos que esse tipo de estudo é relevante não só para discutir a pesquisa, produção e divulgação científica dentro da Área 21 no relacionado com as temáticas indígenas no campo específico da Educação Física, senão também para a abordagem desses conteúdos no processo de formação inicial, pois a partir da Lei 11.645/2008 se faz obrigatório a abordagem destes conteúdos nas escolas de Educação Básica por meio dos diferentes componentes curriculares entre os quais se encontra a Educação Física.

\section{REFERÊNCIAS}

ALBUQUERQUE, Maria do Socorro Craveiro. A Educação Física na Escola Indígena: limites e possibilidades. 1999. 249 f. Dissertação (Mestrado em Educação Escolar) Faculdade de Educação, Universidade Federal do Rio de Janeiro, Rio de Janeiro, 1999.

ANASTÁCIO NETO, Alfredo. A Educação Física na Escola Municipal Indígena "Marcolino Lili": uma possibilidade de fortalecimento étnico. 2007. 145 f. Dissertação (Mestrado) - Universidade Católica Dom Bosco, Campo Grande, 2007.

BENTO, Clóvis Claudino. Jogos de Origem ou Descendência Indígena e Africana na Educação Física Escolar: Educação para e nas Relações Étnico-Raciais. 2012. 104 f. Dissertação (Mestrado em Educação) - Centro de Educação e Ciências Humanas, Universidade Federal de São Carlos, São Carlos, 2012. 
BOARETTO, Juliana Dias; PIMENTEL, Giuliano Gomes de Assis. Os Kaingang do Ivaí, suas danças e a educação intercultural. Movimento, v. 21, n. 3, p. 633-644, jul./set. 2015.

BOSSLE, F.; BOSSLE, C. B. "O conhecimento de quem é mais valioso?" Educação Física Escolar, Educação Crítica e Pesquisa Científica no grupo DIMEEF/UFRGS. In: BOSSLE, F.; BOSSLE, C. B. et al. (org.). Educação Física Escolar, Etnografias e Autoetnografias: a formação de intelectuais transformadores. Curitiba: CRV, 2018. p.15-30.

BRACHT, Valter; FARIA, Bruno de Almeida; ALMEIDA, Felipe Quintão de; GHIDETTI, Filipe Ferreira; GOMES, Ivan Marcelo; ROCHA, Maria Celeste; MACHADO, Thiago da Silva; ALMEIDA, Ueberson Ribeiro; MORAES, Cláudia Emília Aguiar. A Educação Física Escolar como Tema da Produção do Conhecimento nos Periódicos da Área no Brasil (1980-2010) -Parte I. Movimento, v. 17, n. 02, p. 11-34, abr./jun. 2011.

BRASIL. Lei $n^{\circ} \mathbf{1 1 . 6 4 5}$, de 10 março de 2008. Altera a Lei no 9.394, de 20 de dezembro de 1996, modificada pela Lei no 10.639, de 9 de janeiro de 2003, que estabelece as diretrizes e bases da educação nacional, para incluir no currículo oficial da rede de ensino a obrigatoriedade da temática "História e Cultura Afro-Brasileira e Indígena". Brasília, DF. 10 mar. 2008. Disponível em: http://www.planalto.gov.br/ccivil 03/ ato2007-2010/2008/lei/ 111645.htm. Acesso em: 6 ago. 2018.

BRASIL. Ministério da Educação e do Desporto. Lei n 9.394, de 20 de dezembro de 1996, Lei de Diretrizes e Bases da Educação Nacional. Disponível em: http://portal.mec.gov.br/ arquivos/pdf/ldb.pdf. Acesso em: 8 ago. 2018.

BRASIL. Ministério da Educação e do Desporto. Secretaria da Educação Fundamental. Referencial Curricular Nacional para as Escolas Indígenas - RCNEI. Brasília, 1998.

CANON-BUITRAGO, Edwin Alexander. Temáticas indígenas na Educação Física Colombiana: uma análise do discurso do programa de Licenciatura da Universidade Pedagógica Nacional. 2017. 281f. Tese (Doutorado em Ciências do Movimento Humano) Escola de Educação Física, Fisioterapia e Dança, Universidade Federal do Rio Grande do Sul, Porto Alegre, 2017.

CANON-BUITRAGO, Edwin Alexander. naĩ'ãweẽ i nucuma'ü, Jogos Autóctones Ticunas na Perspectiva dos Povos Indígenas da Região Amazônica Colombiana. 2015. Dissertação (Mestrado em Ciências do Movimento Humano) - Escola de Educação Física, Fisioterapia e Dança, Universidade Federal do Rio Grande do Sul, Porto Alegre 2015.

CARMO, Clayton; GONÇALVES, J. Educação física dialógica: uma experiência de intervenção no ensino fundamental. In: CONGRESSO NACIONAL DE EDUCAÇÃO EDUCERE: FORMAÇÃO DE PROFESSORES, 7., edição internacional, 2008, Curitiba. [Anais...]. Curitiba: PUCPR, 2008, v. 8, p. $3078-3090$.

FERREIRA, Gislaine; PIMENTEL, Giuliano Gomes de Assis. Educação Física Intercultural: diálogos com os jogos e brincadeiras Guarani. Horizontes-Revista de Educação, v.1, n.2, p.79-93, jul./dez. 2013.

FREIRE, Paulo. Pedagogia do oprimido. São Paulo: Paz e Terra, 2017.

FREIRE, Paulo. Pedagogia da Tolerância. São Paulo: Unesp, 2005.

FREIRE, Paulo. Pedagogia da Esperança: um reencontro com a Pedagogia do oprimido. 2. ed. Rio de Janeiro: Paz e Terra, 1993.

FREIRE, Paulo; FAUNDEZ, Antonio. Por uma pedagogia da pergunta. Rio de Janeiro: Paz e Terra, 1985. 
FREIRE, Paulo. Conscientização: Teoria e Prática da Libertação uma Teoria ao pensamento de Paulo Freire. São Paulo: Cortez e Moraes, 1979.

GABRIEL, Rosana de Barros. Cultura Indígena: um novo olhar a partir das práticas esportivas e das brincadeiras tradicionais vivenciadas na escola. Revista Corpoconsciência, v. 10, n. 2, p. 6-19, jul./dez. 2006.

GADAMER, Hans-Georg. Verdade e método II. Petrópolis, RJ; Bragança Paulista, SP: Vozes; Editora Universitária São Francisco, 2007.

GOLDSCHMIDT FILHO, Francisco; COELHO, Márcio Cardoso; MULLER, Karine de Almeida; NUNES, Luciana; BOSSLE, Fabiano. Diálogos Sobre o Fazer Ciência em Educação Física Escolar. FÓRUM DE PÓS-GRADUAÇÃO DO COLÉGIO BRASILEIRO DE CIÊNCIAS DO ESPORTE, 6. [Anais...]. Porto Alegre, RS, 1 a 3 de junho de 2016. Disponível em: http://congressos.cbce.org.br/index.php/6FPGCBCE/6Forum/paper/ viewFile/8086/4107. Acesso em: 13 nov. 2018.

HIDALGO, André Vinícius. Educação Física Escolar no curso de formação em nível médio para professores Guarani e Kaiowá: memória da turma 2001. Horizontes - Revista de Educação, v. 3, n. 4, p. 69-81, jul./dez. 2014.

KEMPE, Gédson Cardoso; CHASSOT, Attico Inácio. Práticas corporais indígenas inseridas a Educação Física escolar não indígenas. Revista de Educação Pública, v. 26, n. 62/2, p. 549-567, maio/ago. 2017.

KEMPE, Gédson Cardoso. Práticas corporais indígenas inseridas a Educação Física escolar não indígenas. 2015. 139 f. Dissertação (Mestrado em Reabilitação e Inclusão) Centro Universitário Metodista-IPA, Porto Alegre, 2015.

LEITE, Francinaldo Freitas. Saberes Tradicionais Krahô: Contribuições para Educação Física Bilíngue e Intercultural. 2017. 177 f. Dissertação (Mestrado em Estudos de Cultura e Território) - Universidade Federal do Tocantins, Araguaína, 2017.

MILESKI, Keros Gustavo. A Educação Física na Escola Indígena: A Cidadania e a Emancipação em Questão. 2013. 207 f. Dissertação (Mestrado em Educação) - Centro de Ciências Humanas, Letras e Artes, Universidade Estadual de Maringá, Maringá, 2013.

OLIVEIRA, Ivanilde. A dialogicidade na educação de Paulo Freire e na prática do ensino de Filosofia com crianças. Movimento - Revista de Educação, v.4, n.7, p. 228 - 253, jul./dez. 2017.

PADOIN, Isabel Graciele; VIRGOLIN, Isadora Wayhs Cadore. A vulnerabilidade social como uma dificuldade à participação política. Seminário Interinstitucional de Ensino, Pesquisa e Extensão. Unicruz, 2010. Disponível em: http://www.unicruz.edu.br/15 seminario/seminario_2010/CCSA/A\%20VULNERABILIDADE\%20SOCIAL\%20COMO\%20 UMA $\% 20$ DIFICULDADE $\% 20$ A $\% 20$ PARTICIPA $\%$ C3 $\% 87 \%$ C3\%830\%20POL $\%$ C3\%8DTICA. pdf. Acesso em: 04 set. 2018.

PEREIRA, Jhones Rodrigues. Tessituras da Cultura Corporal em uma Escola Indígena do Alto Rio Negro no Estado do Amazonas. 2013. 135 f. Dissertação (Mestrado em Educação) - Faculdade de Educação, Universidade Federal do Amazonas, Manaus, 2013.

SAMPAIO, Rosana F; MANCINI, MC. Estudos de Revisão Sistemática: um guia para síntese criteriosa da evidência científica. Revista brasileira de fisioterapia, v. 11, n. 1, p. 83-89, jan./fev. 2007. 
SANETO, Juliana Guimarães. Educação Física na/da Escola Indígena: apropriações e ressignificações numa Aldeia Bororo. 2016. 187f. Tese (doutorado) - Faculdade de Educação Física, Universidade Estadual de Campinas, Campinas, 2016.

SANTOS, Maria Jesus. A dialogicidade no pensamento de Paulo Freire e Hans Georg Gadamer e implicações na cultura escolar brasileira. Cadernos do PET Filosofia, v. 5, n. 10, p.01-11, jul./dez. 2017.

SILVA, Renato Izidoro da; BORDAS, Miguel Angel Garcia. O corpo indígena: apontamentos para outra Educação Física. Atos de Pesquisa em Educação, v. 7, n. 2, p. 345-379, maio/ ago. 2012.

WALSH, C. Interculturalidad y colonialidad del poder: Um pensamento y posicionamento "outro" desde la diferencia colonial. In: CASTRO-GOMEZ, S.; GROSFOGUEL, R. (orgs). EI giro Decolonial: reflexiones para una diversidad epistémica más allá del capitalismo global. Bogotá: Siglo del Hombre Editores; Instituto Pensar, 2008. p.47-62.

ZILBERSTEIN, Jacqueline; SKOLAUDE, Lucas Silva; NUNES, Luciana; MEDEIROS, Thiago Nunes; GOULART, Gabriel Gules; BOSSLE, Fabiano. Qualis Capes Periódicos: O (Não) Lugar da Educação Física Escolar na Área 21. FÓRUM DE PÓS-GRADUAÇÃO DO COLÉGIO BRASILEIRO DE CIÊNCIAS DO ESPORTE, 6. [Anais...]. Porto Alegre, RS, 1 a 3 de junho de 2016. Disponível em: http://congressos.cbce.org.br/index. php/6FPGCBCE/6Forum/schedConf/presentations?search/nitial=B\&track=. Acesso em: 15 set.2018. 